\title{
Forecasting risk using auto regressive integrated moving average approach: an evidence from S\&P BSE Sensex
}

\author{
Madhavi Latha Challa ${ }^{1 *}$ D, Venkataramanaiah Malepati ${ }^{2}$ and Siva Nageswara Rao Kolusu ${ }^{1}$
}

\footnotetext{
* Correspondence: saidatta2009@ gmail.com

${ }^{1}$ School of Management Studies, Vignan's Foundation for Science, Technology \& Research, Guntur, Andhra Pradesh, India Full list of author information is available at the end of the article
}

\begin{abstract}
The primary objective of the paper is to forecast the beta values of companies listed on Sensex, Bombay Stock Exchange (BSE). The BSE Sensex constitutes 30 top most companies listed which are popularly known as blue-chip companies. To reach out the predefined objectives of the research, Auto Regressive Integrated Moving Average method is used to forecast the future risk and returns for 10 years of historical data from April 2007 to March 2017. Validation accomplished by comparison of forecasted and actual beta values for the hold back period of 2 years. Root-Mean-Square-Error and Mean-Absolute-Error both are used for accuracy measurement. The results revealed that out of 30 listed companies in the BSE Sensex, 10 companies' exhibits high beta values, 12 companies are with moderate and 8 companies are with low beta values. Further, it is to note that Housing Development Finance Corporation (HDFC) exhibits more inconsistency in terms of beta values though the average beta value is lowest among the companies under the study. A mixed trend is found in forecasted beta values of the BSE Sensex. In this analysis, all the $p$-values are less than the F-stat values except the case of Tata Steel and Wipro. Therefore, the null hypotheses were rejected leaving Tata Steel and Wipro. The values of actual and forecasted values are showing the almost same results with low error percentage. Therefore, it is concluded from the study that the estimation ARIMA could be acceptable, and forecasted beta values are accurate. So far, there are many studies on ARIMA model to forecast the returns of the stocks based on their historical data. But, hardly there are very few studies which attempt to forecast the returns on the basis of their beta values. Certainly, the attempt so made is a novel approach which has linked risk directly with return. On the basis of the present study, authors try to through light on investment decisions by linking it with beta values of respective stocks. Further, the outcomes of the present study undoubtedly useful to academicians, researchers, and policy makers in their respective area of studies.
\end{abstract}

Keywords: Akaike Information Criteria (AIC), Bombay Stock Exchange (BSE), Auto Regressive Integrated Moving Average (ARIMA), Beta, Time series

JEL classification: G12, G14, G17 


\section{Introduction}

The investments in stock market would produce profits as well as losses. But investors want to maximize their profits instead of losses by analyzing stock market conditions. This can be achievable when the risk is predictable in scientific manner. Risk aversion is one of the interesting and important discussions among cult of investors, policy makers, researchers, financial practitioners etc. The movements of returns and risks in the stock market had noteworthy inferences on portfolio diversification and stock market vulnerability. Both risks and returns are two sides of the coin and every successful step undertaken by the investors could be turned into high returns which depend on efficient and rational behavior of investors (Kaufman, G., 1995).

In 1986 the BSE Sensex was started. Gradually it has become the primary proxy for the Bombay Stock Exchange (BSE) and considered as barometer of Indian economy. The free float methodology has been used to calculate index level at any point of time frame and it influences the market movement of 30 largest and actively traded stocks or companies relative to base period. Every day Stock movements are changed because of existence of volatility in market conditions. The BSE Sensex prices are goes up ward direction, when the stocks of major companies on BSE prices gone up and vice versa.

\section{Statement of the problem and research gap}

In recent past, the performance of the stock markets is considered as barometer of economy of a country. But, the appraisal of the performance of the stock market is not so easy in given social, economical and political environment. The stock markets are exhibiting more volatile across the world economies. These fluctuations in the prices of stocks are very wide in developing economies where information asymmetry plays vital role. India, as developing country, it is also not exceptional to the menace of unwanted and excess volatility in the prices of stocks listed in its respective stock markets. Many a times, Indian stock market has witnessed nightmare to millions of investors where they had lost their lifetime savings in a day. In this juncture, the present inquiry concentrates on systematic risk and expected returns of stock in the time horizon because these are uncertain and influences more in behavior of investor. Prediction of return to the given risk associated with a particular security is a common phenomenon but prediction of appropriate stock for investment merely on beta and testing their validity is certainly a novel and it would contribute some addition to the existing literature.

\section{Objectives of the study}

The primary objective of the study is to test the validity of prediction of fruitful stocks on the basis of their beta values with reference to BSE Sensex. Further, the following are the specific objectives. These are: to

(i) Find the beta values of each stock listed on BSE Sensex and determine their degree of risk on the basis of betas so found;

(ii) Compare and contrast each individual stock beta with portfolio's (BSE Sensex) for investment decision making; and

(iii) Validate the accuracy of forecasting risk with actual values over the holding period (test period) of two years. 


\section{Literature review}

Chan and Kwok (2017) examined the roles of risk-sharing and other factors in stock price revaluation during liberalization period in connection to Shanghai Stock Exchange. They have found that risk-sharing was a significant mechanism in price revaluation of stocks. Further, they found strong evidence that market imperfections hindered the incorporation of firm-specific information into stock prices. Furthermore, they added that market liquidity, information asymmetry, and insider trading played a negative role in market efficiency for price adjustment (Brunnermeier, M., Pedersen, L., 2009, Moussa, A., 2011). Asset pricing theory predicts that an asset's expected return is positively associated with its exposure to systematic risk (De Bandt, O., Hartmann, P., 2000, Hansen, L.P., 2013). However, empirical evidence supporting this prediction has been mixed, as it is often found that systematic risk is not priced cross-sectional (e.g., Fama and French, 2004). Chari and Henry (2004) note that stock market liberalizations reduce systematic risk because the relevant source of systematic risk becomes the world market; therefore, liberalizations represent an exogenous change that enables us to test the prediction from theory (Chakrabarty, K.C., (2012).

Jyothi et al. (2017) explains under the unconditional idiosyncratic volatility specification, the firm size, cash flows to price ratio and market capitalizations are significant factors. Moreover they found that size, Liquidity, momentum returns are the determinants under the conditional idiosyncratic volatility. They support under diversified portfolio and suggest based on empirical findings that firm specific fundamentals are significant determinants of unsystematic risk.

The conventional portfolio theory of finance holds that rational investors in perfect capital markets diversify unsystematic risk completely by holding uncorrelated assets in their portfolio (Markowitz 1952), and early theoretical models hypothesize that systematic market risk is the sole determinant of expected stock returns (e.g., Sharpe 1964; Lintner 1965; Black 1976).

Bianconi et al. (2017) examines the effect of information on the top ten financial institution's tail risk and systematic risk by using the information of observed prices of put and call options or newspaper articles. They use Garcia's (2013) data as a measure of CBOE (Chicago Broad of Exchange) volatility Index VIX and market sentiment. They found that very little significant causality using dynamic feedback in terms of volatility.

\section{Research design and methodology}

To reach out the predefined objectives of the study, the data of each company registered on BSE Sensex and the data of BSE Sensex (as a portfolio) from Bombay Stock Exchange Ltd. has been collected for the period of 10 years. For this work, daily open and close prices of stocks registered in BSE Sensex are used as a data. The collected data of each company registered is planned to compare with BSE Sensex as a whole so as to calculate beta values for each company.

\section{BETA calculation}

Beta is a measure to determine the stock market volatility in terms of portfolio or security fluctuations used in fundamental analysis. When evaluating risk, the stock price 
variability is an important consideration. If the risk could be as possibility of reduce the stock value, certainly beta suits as a proxy for risk. The systematic risk of a portfolio measures by Beta. Beta is an important element for capital asset pricing model (CAPM), which calculates the expected return and cost of equity and it is also called beta coefficient. Mathematical formula for Beta is

$$
\operatorname{Beta}=\frac{\text { Coveriance }\left(r_{i}, r_{m}\right)}{\operatorname{Variance}\left(r_{m}\right)}
$$

$r_{i}=$ return of an asset or security (a company registered with Sensex Index)

$r_{m}=$ return of benchmark or market (Sensex Index)

If the beta value of a S\&P BSE Sensex index is 1.0, and individual companies (registered under S\&P BSE Sensex) ranks are found according to this value. An individual stock that slaps more than the S\&P BSE Sensex over the given period of time has a beta could be greater than 1.0. If individual security moves less than the index, that means the beta is less than 1.0. Higher the beta higher the risk as well as higher returns, low risk implies the low risk and low returns.

In portfolio management, the scrip selection is usually based on beta of stocks. Portfolio could be followed in many created ways those are differentiated in several sectors, sector wise, and beta wise portfolio.

\section{ARIMA method}

The ARIMA method was established in 1990s for the prediction of time series(Box and Jenkins 1976).The ARIMA model main notion is over the given period of time it form a predicted object as a random series, to take a data series. To describe the series, a particular statistical technique could be established according to autocorrelation analysis of the time series. Once the technique construct, the future values could be predict through the past and present values of time series. Moreover, in the prediction process of ARIMA model, it considers dependency of the investigated process and the noise of volatility.

An ARIMA(p,d,q) model is defined as an $\mathrm{I}(\mathrm{d})$ process whose $\mathrm{d}^{\text {th }}$ integer difference followsa stationary ARMA(p,q) process. In polynomial form:

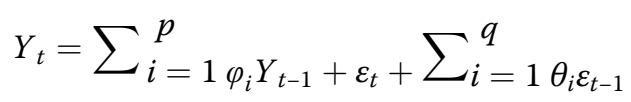

Where.

$Y_{t}=$ differenced time series value.

$\varphi$ and $\theta=$ unknown parameters.

$\varepsilon=$ independent identically distributed error terms with zero mean.

$Y_{t}$ could be expressed as past and current values as well as past error terms.

In ARIMA model, stationarity, invertibility and parsimony are the three important parameters are used to identification, estimation and diagnostic checking respectively (Asteriou and Hall 2015). The mean, variance and covariance are constant over the given time in stationarity process. This could be accomplished by differing either the integrated order one (I (Akaike 1973)) or two(I (Akaike 1974)). In the process of invertibility, $Y_{t}$ measured by convergent autoregressive process (moving average of finite 
order). Box and Jenkins assumed that parsimony is a model, which produce well forecasting with extra coefficients and degree of freedom would be affected. This model is better than an over parameterized model. In this study the ARIMA forecast for the period of March 2017 to April 2019 was modeled by organizing the EViews software which is applied for econometric analysis of time series.

\section{Data}

To reach out the predefined objectives of the study, as the study demands, researchers used exclusively secondary data. The present investigation conducted using daily open and close prices of BSE Sensex. The required data was collected from several resources such as published and unpublished research, magazines, and official website of the BSE.

Table 1 Average year-wise beta values of companies listed in BSE Sensex during 2007-2017

\begin{tabular}{|c|c|c|c|c|c|c|c|c|c|c|c|}
\hline Date & 2008 & 2009 & 2010 & 2011 & 2012 & 2013 & 2014 & 2015 & 2016 & 2017 & Average \\
\hline Tata Motors DVR & 0 & 4.78 & 0.48 & 0.73 & 1.25 & 1.48 & 1.05 & 1.75 & 1.4 & 1.41 & 1.43 \\
\hline ICICI Bank & 1.08 & 1.45 & 1.29 & 1.32 & 1.32 & 1.58 & 1.46 & 1.46 & 1.36 & 1.62 & 1.39 \\
\hline Tata Steel & 1.05 & 1.09 & 1.36 & 1.14 & 1.21 & 1.28 & 1.11 & 1.28 & 1.4 & 1.36 & 1.23 \\
\hline State Bank of India & 1.14 & 1.08 & 1.03 & 0.87 & 1.15 & 1.42 & 1.18 & 1.31 & 1.3 & 1.56 & 1.20 \\
\hline Tata Motors & 0.94 & 0.64 & 1.44 & 1.14 & 1.2 & 1.34 & 1.01 & 1.49 & 1.37 & 1.39 & 1.20 \\
\hline Axis Bank & 0.53 & 1.46 & 1.1 & 1.08 & 1.23 & 1.34 & 1.46 & 1.39 & 1.13 & 1.24 & 1.20 \\
\hline Larsen \& Toubro & 1.14 & 1.08 & 1.26 & 0.84 & 1.2 & 1.48 & 1.37 & 1.29 & 1.16 & 1.12 & 1.19 \\
\hline Kotak Mahindra Bank & 1.37 & 1.36 & 1.12 & 0.87 & 1.2 & 1.03 & 1.33 & 0.92 & 0.92 & 0.72 & 1.08 \\
\hline Adani Ports \& SEZ & 1.59 & 0.56 & 0.69 & 0.89 & 0.71 & 0.95 & 0.75 & 1.69 & 1.05 & 1.61 & 1.05 \\
\hline Reliance Industries & 1.24 & 1.16 & 0.99 & 0.87 & 1.14 & 0.9 & 1.1 & 1.11 & 1.07 & 0.74 & 1.03 \\
\hline Mahindra \& Mahindra & 0.84 & 0.84 & 1.13 & 0.93 & 1.13 & 0.78 & 0.89 & 0.93 & 1.04 & 1.13 & 0.96 \\
\hline HDFC Bank & 1.02 & 0.99 & 0.63 & 0.81 & 0.93 & 0.96 & 1.29 & 0.93 & 0.69 & 0.74 & 0.90 \\
\hline Oil and Natural Gas Corporation & 0.39 & 0.54 & 0.7 & 0.5 & 0.7 & 1.09 & 1.16 & 1.31 & 1.16 & 0.62 & 0.82 \\
\hline Maruti Suzuki & 0.75 & 0.66 & 0.6 & 0.54 & 0.73 & 0.69 & 0.71 & 1 & 0.81 & 1.17 & 0.77 \\
\hline BhartiAirtel & 0.97 & 0.78 & 0.56 & 0.64 & 0.81 & 0.72 & 1.13 & 0.45 & 0.57 & 0.81 & 0.74 \\
\hline NTPC & 1.04 & 0.68 & 0.54 & 0.38 & 0.74 & 0.68 & 0.69 & 1.07 & 0.69 & 0.86 & 0.74 \\
\hline ITC & 0.48 & 0.59 & 0.84 & 0.53 & 0.55 & 0.73 & 0.9 & 0.62 & 0.91 & 0.94 & 0.71 \\
\hline Coal India & & & & 0.68 & 0.53 & 0.47 & 0.63 & 1.1 & 0.75 & 0.6 & 0.68 \\
\hline Power Grid Corporation of India & 1.13 & 0.7 & 0.52 & 0.36 & 0.54 & 0.69 & 0.63 & 0.74 & 0.49 & 0.86 & 0.67 \\
\hline Tata Consultancy Services & 0.67 & 0.95 & 0.62 & 0.74 & 0.87 & 0.57 & 0.62 & 0.49 & 0.55 & 0.45 & 0.65 \\
\hline Hero MotoCorp & 0.6 & 0.3 & 0.58 & 0.55 & 0.53 & 0.53 & 0.74 & 0.72 & 0.82 & 1.01 & 0.64 \\
\hline Infosys & 0.64 & 0.7 & 0.56 & 0.63 & 0.79 & 0.62 & 0.43 & 0.3 & 0.82 & 0.69 & 0.62 \\
\hline Cipla & 0.34 & 0.41 & 0.5 & 0.44 & 0.49 & 0.57 & 0.44 & 0.66 & 0.9 & 0.51 & 0.53 \\
\hline Lupin & 0.58 & 0.52 & 0.25 & 0.59 & 0.36 & 0.37 & 0.32 & 0.41 & 0.78 & 0.87 & 0.51 \\
\hline Sun Pharmaceutical & 0.32 & 0.28 & 0.37 & 0.48 & 0.46 & 0.41 & 0.54 & 0.34 & 0.94 & 0.86 & 0.50 \\
\hline Wipro & -0.14 & 0.63 & 0.92 & 0.67 & 0.73 & 0.54 & 0.34 & 0.38 & 0.48 & 0.43 & 0.50 \\
\hline Asian Paints & 0.21 & 0.09 & 0.25 & 0.19 & 0.25 & 0.73 & 0.72 & 0.85 & 0.71 & 0.82 & 0.48 \\
\hline Hindustan Unilever & 0.5 & 0.38 & 0.37 & 0.41 & 0.55 & 0.53 & 0.6 & 0.15 & 0.58 & 0.45 & 0.45 \\
\hline Dr. Reddy's Laboratories & 0.34 & 0.42 & 0.4 & 0.27 & 0.49 & 0.26 & 0.52 & 0.27 & 0.67 & 0.56 & 0.42 \\
\hline $\begin{array}{l}\text { Housing Development Finance } \\
\text { Corporation }\end{array}$ & 0.55 & 0.48 & 0.43 & 0.43 & 0.49 & -0.79 & 0.6 & 0.49 & 0.72 & -0.46 & 0.29 \\
\hline
\end{tabular}

Source: Compiled by authors 
The collected was processed and tabulated as per the needs of the study. It covers the period of 10 years from April 2007 to March 2017.

\section{Scope and limitations of the study}

No study is exceptional to the completeness. The present study covers only BSE Sensex leaving all the sectorial indices incorporated within otherwise these would have included under the coverage of the study. Further, along the BSE, there other national stock exchanges which are also considered as imperative stock exchanges in Indian economy. But due to time, difficulty to arrive uniformity in some variables they were ignored for the study.

\section{Results and discussion}

The following paragraphs are devoted to discuss the results arrived through the methodology adopted for the purpose.

Table 1 exhibits average year-wise beta values of companies listed in BSE Sensex during 2007-2017. It can be understand that those companies' beta values which are having more than one are more volatile in movement of prices of stocks; those who are having less than one are less volatile. If the beta is near to one, the volatility of the movement of the prices of the market equals to that of the movement of the prices of individual company of portfolio/index. Usually, investors prefer less than 1 beta value companies because these stocks are having less volatility, low risk and also lower

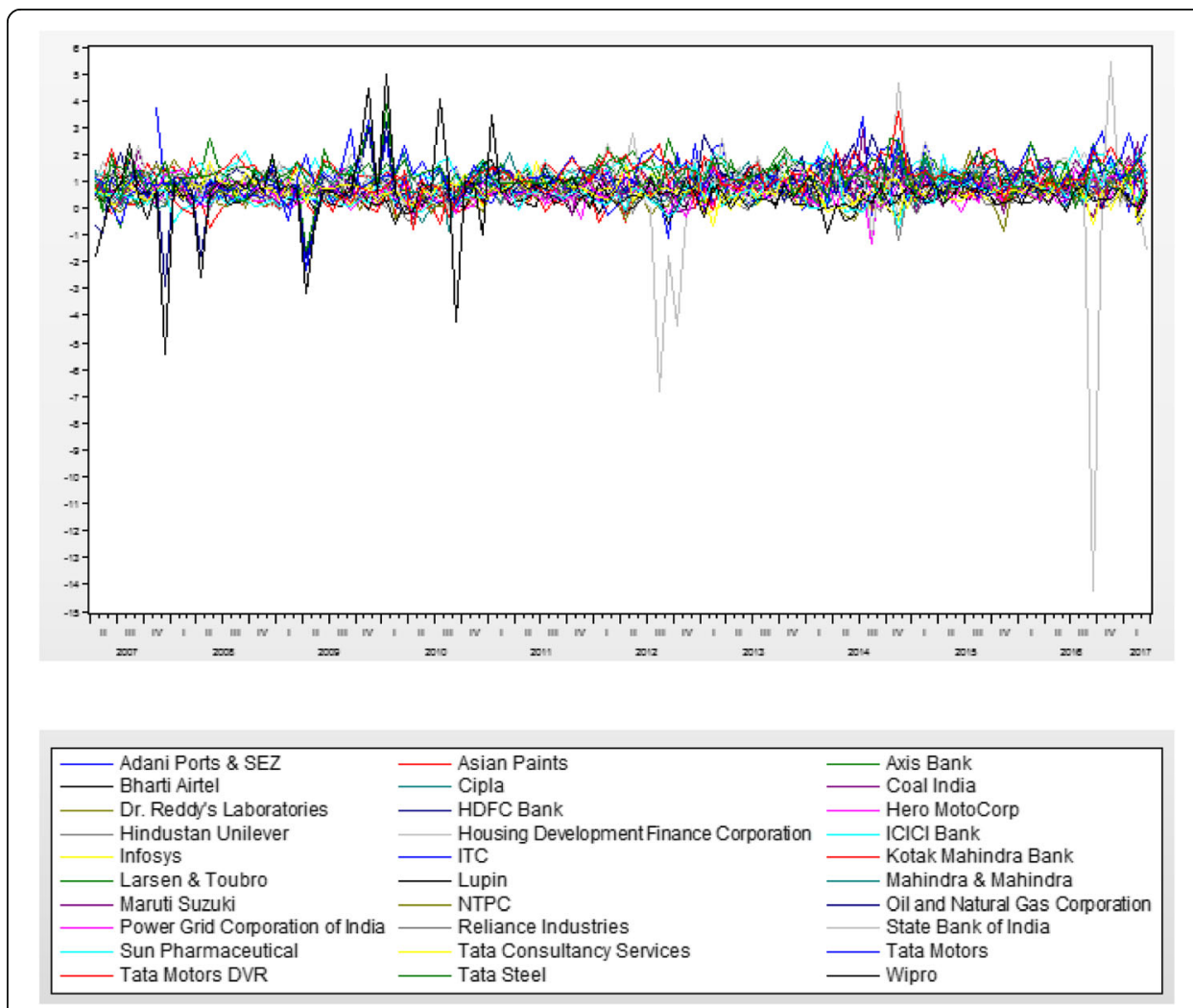

Fig. 1 Summary of average year-wise beta values of companies listed in BSE Sensex during 2008-17 
returns. Generally, higher beta means firms with more returns. Hence, expected growth is also associated with high risk and uncertainty.

A glance at the Table 1 reveals that the average beta of Tata Motors Differential Voting Right Share (DVR) is1.43 followed by ICICI Bank (1.39), Tata Steel (1.23) SBI (1.20), Tata Motors (1.20), Axis Bank (1.20), L and T (1.19), Kotak Mahendra (1.08), Adani Ports and SEZ (1.05), Reliance Industries (1.03) serially. The companies exhibiting highest volatility as the beta values of these companies are more than one. Further, HDFC, Dr. Reddy's Laboratories, Hindustan Unilever, Wipro, Sun Pharmacetical, Lupin and Cipla companies exhibits low average beta values. The beta value of the companies under the study demonstrates moderate beta values ranges from 0.96 to 0.62 . Out of 30 listed companies in the BSE Sensex, 10 companies' exhibits high beta values, 12 companies are with moderate beta values and 8 companies are with low beta values. It is interesting to note that Housing Development Finance Corporation (HDFC) exhibits more inconsistency in

Table 2 ADF test result

\begin{tabular}{|c|c|}
\hline Companies & T - Stats \\
\hline Adani Ports \& SEZ & -8.89914 \\
\hline Asian Paints & -7.73641 \\
\hline Axis Bank & -5.83681 \\
\hline BhartiAirtel & -8.06226 \\
\hline Cipla & -6.63636 \\
\hline Coal India & -4.7765 \\
\hline Dr. Reddy's Laboratories & -8.09778 \\
\hline HDFC Bank & -12.0394 \\
\hline Hero MotoCorp & -5.88376 \\
\hline Hindustan Unilever & -5.19454 \\
\hline Housing Development Finance Corporation & -6.72789 \\
\hline IClCl Bank & -9.00227 \\
\hline Infosys & -9.01065 \\
\hline ITC & -6.04998 \\
\hline Kotak Mahindra Bank & -7.82484 \\
\hline Larsen \& Toubro & -6.70005 \\
\hline Lupin & -9.07992 \\
\hline Mahindra \& Mahindra & -5.79195 \\
\hline Maruti Suzuki & -6.08925 \\
\hline NTPC & -8.75293 \\
\hline Oil and Natural Gas Corporation & -6.41211 \\
\hline Power Grid Corporation of India & -6.77208 \\
\hline Reliance Industries & -6.04827 \\
\hline State Bank of India & -6.96081 \\
\hline Sun Pharmaceutical & -7.34285 \\
\hline Tata Consultancy Services & -9.43277 \\
\hline Tata Motors & -6.33196 \\
\hline Tata Motors DVR & -8.21388 \\
\hline Tata Steel & -8.57442 \\
\hline Wipro & -8.71443 \\
\hline
\end{tabular}

Source: Compiled by authors 
terms of beta values though the average beta value is lowest among the companies under the study. Furthermore, it can be observed that HDFC and Wipro are two companies which exhibit negative beta values over the period of study (see Fig. 1).

The following paragraphs present the sequence of results i.e., Identification, Estimation, Diagnostic check, Forecasting and Validation.

\section{Identification}

In this stage, the Augmented Dickie Fuller (ADF) test is used to ensure the level of data series is stationary or not. The result of ADF test shows that the series has achieved a stationary state. The stationary could be identified according to the $t$-stats value. If the $t$-stats

Table 3 Akaike Information Criteria value (AIC)

\begin{tabular}{|c|c|c|}
\hline Companies & Selected ARMA model & AIC value \\
\hline Adani Ports \& SEZ & (Akaike 1974; Akaike 1979)(0,0) & 2.419996205 \\
\hline Asian Paints & $(0,1)(0,2)$ & 1.18300953 \\
\hline Axis Bank & (Akaike 1974; Akaike 1976)(0,0) & 1.412734755 \\
\hline BhartiAirtel & (Akaike 1974; Akaike 1979)(0,0) & 1.126284533 \\
\hline Cipla & $(0,2)(0,0)$ & 1.036260176 \\
\hline Coal India & $(2,0)(0,0)$ & 1.383862705 \\
\hline Dr. Reddy's Laboratories & (Akaike 1974)(0,0) & 1.021199203 \\
\hline HDFC Bank & $(4,0)(0,0)$ & 0.865074133 \\
\hline Hero MotoCorp & (Akaike 1973; Akaike 1976)(0,0) & 1.398471031 \\
\hline Hindustan Unilever & $(0,2)$ (Akaike 1973) & 0.912515275 \\
\hline $\begin{array}{l}\text { Housing Development Finance } \\
\text { Corporation }\end{array}$ & $(0,0)(0,0)$ & 3.890160664 \\
\hline $\mathrm{ICICI}$ Bank & $(0,2)$ (Akaike 1973; Akaike 1974) & 0.576514289 \\
\hline Infosys & (Akaike 1976) (Akaike 1973) & 0.784789316 \\
\hline ITC & $(0,2)(0,0)$ & 1.75706519 \\
\hline Kotak Mahindra Bank & (Akaike 1973; Akaike 1974)(0,0) & 1.126330283 \\
\hline Larsen \& Toubro & (Akaike 1974)(0,0) & 1.669414571 \\
\hline Lupin & $(1,0)(0,0)$ & 1.201107512 \\
\hline Mahindra \& Mahindra & (Akaike 1979)(0,0) & 1.26508819 \\
\hline Maruti Suzuki & $(0,1)(0,0)$ & 1.595029239 \\
\hline NTPC & $\begin{array}{l}\text { (Akaike 1974; Akaike 1976) (Akaike 1973; Akaike } \\
\text { 1974) }\end{array}$ & 0.916387604 \\
\hline Oil and Natural Gas Corporation & $(0,1)(1,0)$ & 2.473119679 \\
\hline Power Grid Corporation of India & $(1,0)(0,0)$ & 1.028937003 \\
\hline Reliance Industries & (Akaike 1974)(0,1) & 0.472093637 \\
\hline State Bank of India & $(0,1)(0,0)$ & 2.040875765 \\
\hline Sun Pharmaceutical & (Akaike 1974; Akaike 1979)(1,0) & 1.113411517 \\
\hline Tata Consultancy Services & (Akaike 1974; Akaike 1976) (Akaike 1973) & 1.105677727 \\
\hline Tata Motors & (Akaike 1974; Akaike 1976) (Akaike 1973) & 1.542142809 \\
\hline Tata Motors DVR & (Akaike 1974; Akaike 1976)(0,2) & 1.827594151 \\
\hline Tata Steel & (Akaike 1974)(0,0) & 1.449933246 \\
\hline Wipro & $(0,0)(1,0)$ & 3.207891726 \\
\hline
\end{tabular}

Source: Compiled by authors 
value is greater than the critical value (CV) at $5 \%$ level i.e. -2.888157 , then it is considered as stationary. In the present study, the calculated values of ADF test of all the companies under the study are greater than that of critical values at $5 \%$ level of significance (Table 2).

\section{Estimation}

In this estimation stage, different ARIMA models are estimated using Akaike Information Criteria (AIC) for comparison (Akaike 1981). AIC is used to determine the model best fits a set of data series and it choose the best model to forecast the future data. This is based upon the estimated log-likelihood of the model, number of observations and number of parameters in the model. By using ARIMA models, the number of Auto Regressive Moving Average (ARMA) terms could be determined. The maximum number of Auto Regressive (AR) or Moving Average (MA) coefficients has been specified to determine the number of ARMA terms, then to estimate every model up to those maxima and then each model could be evaluated using its information criterion.

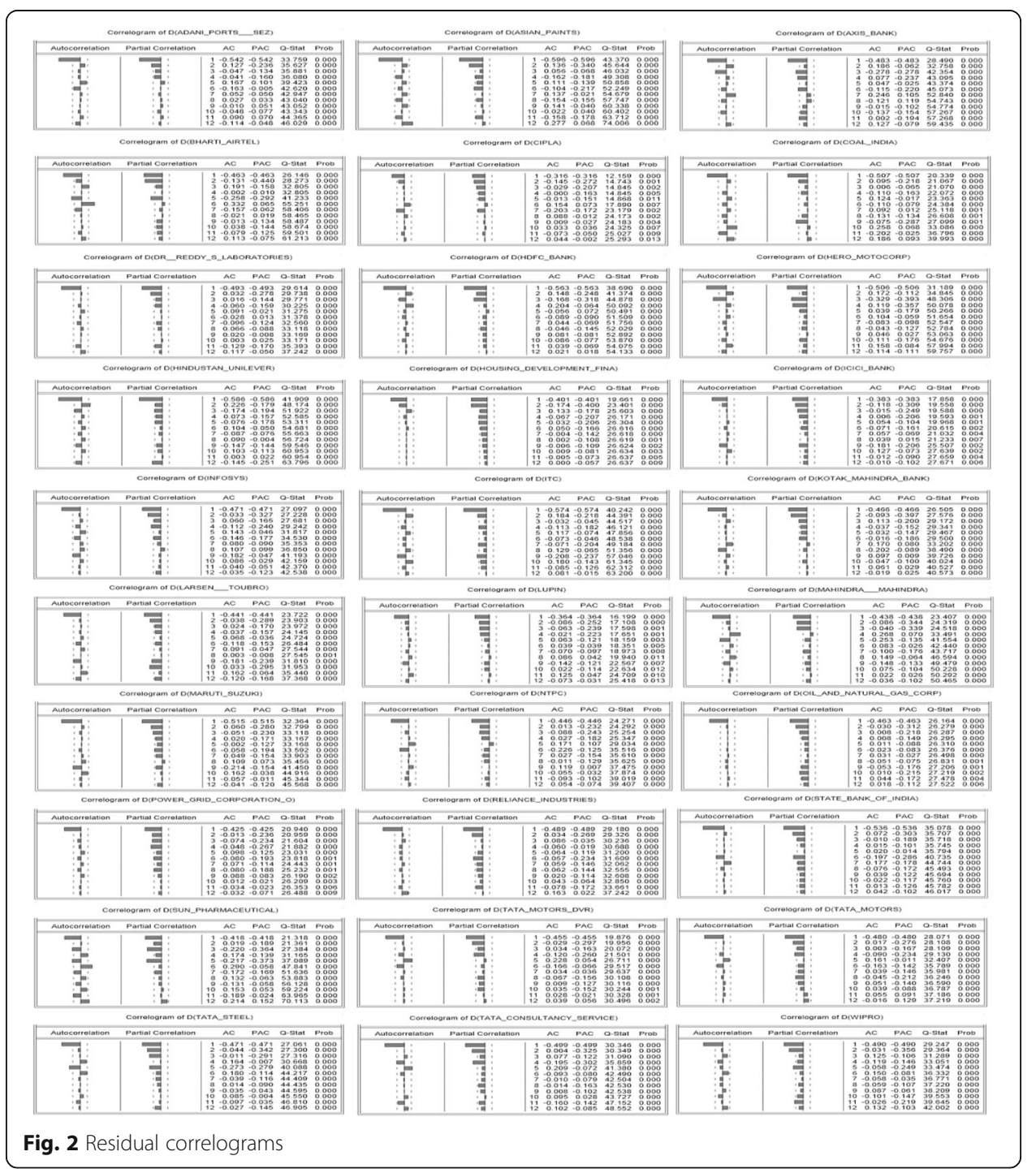


After estimating each model along with calculated criterion, the model could be chosen with the lowest criterion value. According to Stone (1981) and Lindley (1968), the selection of best model represented by parsimony of parameters, it can take variety of attributes of the chosen model. In this analysis, the estimated ARMA models are 225. The selected models along with AIC values are presented in Table 3.

\section{Diagnostic check}

The diagnostic check is essential check as it is used to check whether the residuals have white noise characteristics or not. The Auto Correlation Function (ACF) and Partial

Table 4 Forecasted beta values of companies of BSE Sensex using ARIMA for the financial year 2017-18

\begin{tabular}{|c|c|c|c|c|c|c|c|c|c|c|c|c|c|}
\hline Date & Apr & May & June & July & Aug & Sep & Oct & Nov & Dec & Jan & Feb & Mar & Average \\
\hline \multicolumn{14}{|l|}{ Company } \\
\hline Adani Ports \& SEZ & 1.72 & 2.34 & 2.25 & 1.96 & 2.48 & 2.30 & 2.21 & 2.61 & 2.4 & 2.43 & 2.72 & 2.54 & 2.33 \\
\hline IClCl Bank & 1.32 & 1.64 & 1.49 & 1.23 & 1.41 & 1.54 & 1.79 & 1.58 & 1.46 & 1.59 & 1.46 & 1.65 & 1.51 \\
\hline Tata Motors DVR & 1.24 & 1.62 & 1.57 & 1.57 & 1.33 & 1.48 & 1.9 & 1.42 & 1.65 & 1.38 & 1.45 & 1.41 & 1.50 \\
\hline State Bank of India & 1.45 & 1.46 & 1.46 & 1.47 & 1.47 & 1.48 & 1.48 & 1.48 & 1.49 & 1.49 & 1.50 & 1.50 & 1.48 \\
\hline Tata Motors & 1.13 & 1.42 & 1.45 & 1.70 & 1.67 & 1.55 & 1.61 & 1.31 & 1.34 & 1.37 & 1.46 & 1.61 & 1.47 \\
\hline Tata Steel & 1.26 & 0.99 & 1.40 & 1.30 & 1.00 & 1.35 & 1.34 & 1.02 & 1.30 & 1.36 & 1.04 & 1.26 & 1.22 \\
\hline Axis Bank & 1.35 & 1.15 & 1.29 & 1.15 & 1.21 & 1.22 & 1.15 & 1.26 & 1.13 & 1.24 & 1.18 & 1.18 & 1.21 \\
\hline Larsen \& Toubro & 1.27 & 1.32 & 1.34 & 1.33 & 1.28 & 1.22 & 1.15 & 1.09 & 1.06 & 1.06 & 1.09 & 1.14 & 1.20 \\
\hline Maruti Suzuki & 0.99 & 0.99 & 1.00 & 1.00 & 1.00 & 1.01 & 1.01 & 1.01 & 1.02 & 1.02 & 1.03 & 1.03 & 1.01 \\
\hline Reliance Industries & 0.87 & 1.08 & 1.00 & 1.08 & 1.08 & 0.81 & 0.93 & 0.96 & 0.98 & 0.91 & 0.94 & 1.10 & 0.99 \\
\hline Mahindra \& Mahindra & 0.81 & 1.12 & 1.02 & 1.30 & 0.8 & 0.98 & 0.74 & 0.97 & 1.02 & 1.03 & 1.08 & 0.88 & 0.98 \\
\hline Asian Paints & 0.94 & 0.82 & 0.97 & 1.07 & 1.04 & 0.99 & 0.65 & 0.80 & 0.95 & 0.77 & 0.97 & 1.04 & 0.92 \\
\hline Hero MotoCorp & 0.61 & 0.62 & 1.00 & 0.99 & 0.99 & 0.88 & 0.88 & 0.89 & 0.93 & 0.94 & 0.94 & 0.93 & 0.88 \\
\hline Sun Pharmaceutical & 0.72 & 1.05 & 0.52 & 1.03 & 0.53 & 1.10 & 0.60 & 1.10 & 0.65 & 1.02 & 0.62 & 1.05 & 0.83 \\
\hline NTPC & 0.97 & 0.76 & 1.00 & 0.63 & 0.82 & 0.66 & 0.89 & 0.93 & 0.89 & 0.61 & 0.9 & 0.82 & 0.82 \\
\hline Kotak Mahindra Bank & 1.12 & 0.58 & 1.02 & 0.64 & 0.95 & 0.68 & 0.89 & 0.71 & 0.86 & 0.73 & 0.83 & 0.74 & 0.81 \\
\hline HDFC Bank & 0.82 & 0.67 & 0.88 & 0.70 & 0.81 & 0.77 & 0.82 & 0.79 & 0.82 & 0.81 & 0.82 & 0.81 & 0.79 \\
\hline ONGC & 0.79 & 0.81 & 0.76 & 0.96 & 0.87 & 0.75 & 0.66 & 0.82 & 0.81 & 0.98 & 0.55 & 0.67 & 0.79 \\
\hline ITC & 0.93 & 0.89 & 0.71 & 0.71 & 0.71 & 0.71 & 0.71 & 0.71 & 0.71 & 0.71 & 0.71 & 0.71 & 0.74 \\
\hline BhartiAirtel & 0.71 & 0.39 & 0.96 & 0.75 & 0.55 & 0.89 & 0.72 & 0.67 & 0.81 & 0.74 & 0.7 & 0.79 & 0.72 \\
\hline Cipla & 0.67 & 0.70 & 0.70 & 0.71 & 0.71 & 0.71 & 0.72 & 0.72 & 0.72 & 0.72 & 0.73 & 0.73 & 0.71 \\
\hline Coal India & 0.66 & 0.61 & 0.67 & 0.67 & 0.68 & 0.68 & 0.68 & 0.68 & 0.68 & 0.68 & 0.68 & 0.68 & 0.67 \\
\hline $\begin{array}{l}\text { Power Grid Corporation of } \\
\text { India }\end{array}$ & 0.64 & 0.64 & 0.64 & 0.64 & 0.64 & 0.64 & 0.64 & 0.64 & 0.64 & 0.64 & 0.64 & 0.64 & 0.64 \\
\hline Infosys & 0.44 & 0.55 & 0.61 & 0.44 & 0.78 & 0.6 & 0.71 & 0.64 & 0.49 & 0.7 & 0.76 & 0.60 & 0.61 \\
\hline Lupin & 0.51 & 0.51 & 0.51 & 0.51 & 0.51 & 0.51 & 0.51 & 0.51 & 0.51 & 0.51 & 0.51 & 0.51 & 0.51 \\
\hline Wipro & 0.52 & 0.47 & 0.36 & 0.54 & 0.54 & 0.43 & 0.45 & 0.45 & 0.53 & 0.44 & 0.39 & 0.53 & 0.47 \\
\hline Hindustan Unilever & 0.21 & 0.39 & 0.31 & 0.45 & 0.36 & 0.39 & 0.54 & 0.73 & 0.46 & 0.5 & 0.42 & 0.52 & 0.44 \\
\hline Tata Consultancy Services & 0.50 & 0.51 & 0.4 & 0.52 & 0.4 & 0.35 & 0.5 & 0.44 & 0.4 & 0.5 & 0.2 & 0.51 & 0.44 \\
\hline Dr. Reddy's Laboratories & 0.36 & 0.34 & 0.32 & 0.31 & 0.31 & 0.32 & 0.34 & 0.36 & 0.38 & 0.41 & 0.43 & 0.45 & 0.36 \\
\hline $\begin{array}{l}\text { Housing Development } \\
\text { Finance Corporation }\end{array}$ & 0.29 & 0.29 & 0.29 & 0.29 & 0.29 & 0.29 & 0.29 & 0.29 & 0.29 & 0.29 & 0.29 & 0.29 & 0.29 \\
\hline
\end{tabular}


Auto Correlation Function (PACF) are used to avoid spurious forecast and ensure that residuals should not be auto correlated. In this analysis, to plot the correlogram of the beta series with the first difference, which is represented by $d(x)=x-x(-1)$, and lag of 12 series has been chosen. The Fig. 2 depicts 12 series of beta values of the correlogram and associated statistics. The two standard error bounds are represented by dotted lines in the AC and PAC, which is calculated by $\pm 2 /(\sqrt{T})$. The AC and PAC are not significantly different from zero at the 5\% significance level, when the AC and PAC are within the bounds. The following correlation diagrams Fig. 2 shows that there is no evidence

Table 5 Forecasted beta values of companies of BSE Sensex using ARIMA for the financial year 2018-19

\begin{tabular}{|c|c|c|c|c|c|c|c|c|c|c|c|c|c|}
\hline $\begin{array}{l}\text { Date } \\
\text { Company }\end{array}$ & Apr & May & Jun & July & Aug & Sep & Oct & Nov & Dec & Jan & Feb & Mar & Average \\
\hline Adani Ports \& SEZ & 2.65 & 2.83 & 2.70 & 2.85 & 2.96 & 2.88 & 3.04 & 3.10 & 3.07 & 3.22 & 3.26 & 3.26 & 2.99 \\
\hline IClCI Bank & 1.80 & 1.55 & 1.68 & 2.09 & 1.77 & 1.71 & 1.52 & 1.69 & 1.67 & 1.57 & 1.85 & 1.60 & 1.71 \\
\hline Tata Motors DVR & 1.81 & 1.56 & 1.29 & 1.13 & 1.42 & 1.99 & 1.90 & 1.65 & 1.35 & 1.50 & 1.94 & 1.82 & 1.61 \\
\hline Tata Motors & 1.77 & 1.66 & 1.68 & 1.49 & 1.45 & 1.46 & 1.39 & 1.61 & 1.64 & 1.70 & 1.69 & 1.61 & 1.60 \\
\hline State Bank of India & 1.50 & 1.51 & 1.51 & 1.52 & 1.52 & 1.53 & 1.53 & 1.53 & 1.54 & 1.54 & 1.55 & 1.55 & 1.53 \\
\hline Tata Steel & 1.38 & 1.07 & 1.22 & 1.38 & 1.10 & 1.19 & 1.38 & 1.13 & 1.16 & 1.37 & 1.17 & 1.15 & 1.23 \\
\hline Larsen \& Toubro & 1.21 & 1.27 & 1.31 & 1.33 & 1.31 & 1.27 & 1.21 & 1.15 & 1.10 & 1.07 & 1.07 & 1.10 & 1.20 \\
\hline Axis Bank & 1.23 & 1.14 & 1.24 & 1.16 & 1.21 & 1.20 & 1.17 & 1.23 & 1.15 & 1.22 & 1.18 & 1.19 & 1.19 \\
\hline Maruti Suzuki & 1.03 & 1.04 & 1.04 & 1.04 & 1.05 & 1.05 & 1.06 & 1.06 & 1.06 & 1.07 & 1.07 & 1.07 & 1.05 \\
\hline Reliance Industries & 0.98 & 1.00 & 1.04 & 1.07 & 1.07 & 1.05 & 1.02 & 1.01 & 1.01 & 1.03 & 1.05 & 1.05 & 1.03 \\
\hline Asian Paints & 1.01 & 0.96 & 0.97 & 1.04 & 1.08 & 1.05 & 0.81 & 1.07 & 1.12 & 0.86 & 1.14 & 1.22 & 1.03 \\
\hline Hero MotoCorp & 0.94 & 0.94 & 0.95 & 0.95 & 0.96 & 0.96 & 0.97 & 0.97 & 0.97 & 0.98 & 0.98 & 0.99 & 0.96 \\
\hline Mahindra \& Mahindra & 0.96 & 0.86 & 0.99 & 0.99 & 1.00 & 0.99 & 0.92 & 0.96 & 0.92 & 0.99 & 0.97 & 0.99 & 0.96 \\
\hline Sun Pharmaceutical & 0.70 & 0.99 & 0.73 & 0.96 & 0.78 & 0.93 & 0.83 & 0.90 & 0.89 & 0.86 & 0.93 & 0.83 & 0.86 \\
\hline $\begin{array}{l}\text { Oil and Natural } \\
\text { Gas Corporation }\end{array}$ & 0.84 & 0.85 & 0.84 & 0.88 & 0.87 & 0.85 & 0.83 & 0.87 & 0.87 & 0.91 & 0.82 & 0.85 & 0.86 \\
\hline HDFC Bank & 0.82 & 0.82 & 0.83 & 0.83 & 0.83 & 0.83 & 0.83 & 0.83 & 0.83 & 0.83 & 0.83 & 0.83 & 0.83 \\
\hline Kotak Mahindra Bank & 0.80 & 0.74 & 0.78 & 0.74 & 0.77 & 0.74 & 0.76 & 0.73 & 0.74 & 0.73 & 0.73 & 0.72 & 0.75 \\
\hline Cipla & 0.73 & 0.74 & 0.74 & 0.74 & 0.74 & 0.75 & 0.75 & 0.75 & 0.76 & 0.76 & 0.76 & 0.76 & 0.75 \\
\hline BhartiAirtel & 0.73 & 0.73 & 0.76 & 0.74 & 0.73 & 0.76 & 0.74 & 0.74 & 0.75 & 0.75 & 0.74 & 0.75 & 0.74 \\
\hline NTPC & 0.89 & 0.68 & 0.74 & 0.69 & 0.86 & 0.65 & 0.80 & 0.48 & 0.78 & 0.74 & 0.73 & 0.63 & 0.72 \\
\hline ITC & 0.71 & 0.71 & 0.71 & 0.71 & 0.71 & 0.71 & 0.71 & 0.71 & 0.71 & 0.71 & 0.71 & 0.71 & 0.71 \\
\hline Coal India & 0.68 & 0.68 & 0.68 & 0.68 & 0.68 & 0.68 & 0.68 & 0.68 & 0.68 & 0.68 & 0.68 & 0.68 & 0.68 \\
\hline $\begin{array}{l}\text { Power Grid Corporation } \\
\text { of India }\end{array}$ & 0.64 & 0.64 & 0.64 & 0.64 & 0.64 & 0.64 & 0.64 & 0.64 & 0.64 & 0.64 & 0.64 & 0.64 & 0.64 \\
\hline Infosys & 0.55 & 0.52 & 0.66 & 0.48 & 0.72 & 0.65 & 0.63 & 0.68 & 0.50 & 0.67 & 0.76 & 0.56 & 0.62 \\
\hline Lupin & 0.51 & 0.51 & 0.51 & 0.51 & 0.51 & 0.51 & 0.51 & 0.51 & 0.51 & 0.51 & 0.51 & 0.51 & 0.51 \\
\hline Wipro & 0.49 & 0.48 & 0.46 & 0.49 & 0.49 & 0.47 & 0.47 & 0.48 & 0.49 & 0.47 & 0.46 & 0.49 & 0.48 \\
\hline Dr. Reddy's Laboratories & 0.47 & 0.48 & 0.49 & 0.49 & 0.49 & 0.48 & 0.46 & 0.45 & 0.43 & 0.41 & 0.40 & 0.39 & 0.45 \\
\hline Hindustan Unilever & 0.36 & 0.44 & 0.37 & 0.45 & 0.39 & 0.41 & 0.51 & 0.62 & 0.45 & 0.48 & 0.43 & 0.49 & 0.45 \\
\hline Tata Consultancy Services & 0.39 & 0.38 & 0.48 & 0.38 & 0.46 & 0.49 & 0.38 & 0.42 & 0.44 & 0.35 & 0.60 & 0.34 & 0.43 \\
\hline $\begin{array}{l}\text { Housing Development } \\
\text { Finance Corporation }\end{array}$ & 0.29 & 0.29 & 0.29 & 0.29 & 0.29 & 0.29 & 0.29 & 0.29 & 0.29 & 0.29 & 0.29 & 0.29 & 0.29 \\
\hline
\end{tabular}

Source: Compiled by authors 
and signs of standard error and all of the spikes were within the standard error bars as shown in Fig. 2.

\section{Forecasting}

The forecasting stage is used to find the future beta values for a single series based upon an ARIMA model using the automatic ARIMA forecasting method by E-views software. It allows the user to determine the appropriate specification of ARIMA. It is also useful to forecast the future data series. Forecasted values of companies of BSE Sensex using ARIMA for the period of study are portrayed in Table 4.

It can be observed from the Table 1 that the beta values of companies under study exhibits incremental growth in their respective beta values leaving few companies when we compare the beta values between April 2017 and March 2018. Axis Bank, L and T, NTPC, Kotak Mahindra Bank, HDFC Bank, ITC and Cola India companies under the study are exhibited a reverse trend with decline of beta values between April 2017 and March 2018. A very few companies did not shown any major movements during the forecasted period.

Forecasted beta values of companies under the study are shown in Table 5. A glance at the table reveals there is a mixed trend in the growth/decline of beta values of companies under the study for the reference period. The average beta value is highest in Adani Ports and SEZ (2.99) while the lowest is recorded in HDFC (0.29).

Tables 4 and 5 represent the forecasted beta values to estimate the risk in the future. From the Tables 4 and 5 authors analyze three categories of investment risks. These are defensive, moderate and aggressive betas. Based on these three kinds of risks, investors can choose the company that they would like to invest on the basis of their risk bearing capacity. If the beta is greater than one then the risk is more as well as returns too. If the beta is near to one or equal to one, then it is said to be that the volatility or fluctuations of the company equals to the market. If the beta value is less than one it attributes less risk with less returns.

Historical and forecasted beta values of companies under the study for the reference period after applying the ARIMA process are exhibited in Fig. 3.

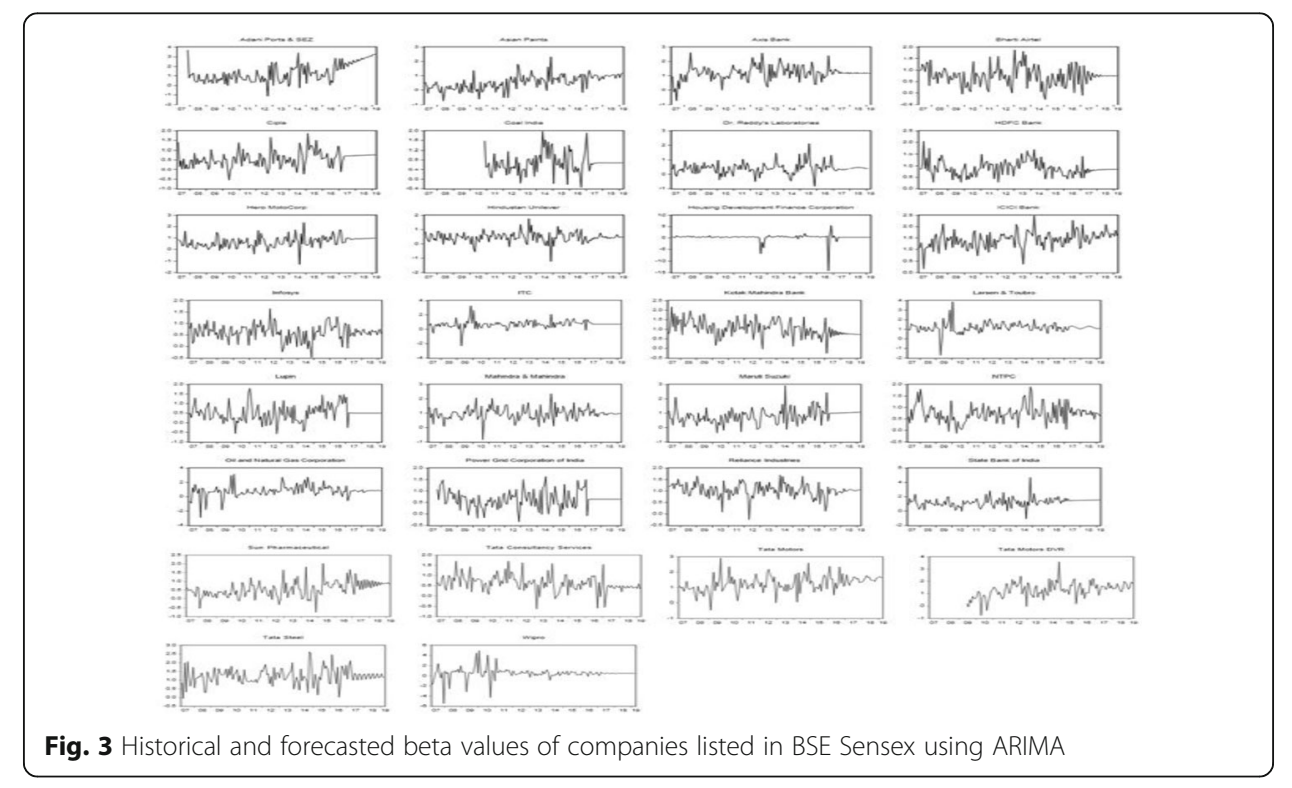


Table 6 Summary results of Auto ARIMA

\begin{tabular}{|c|c|c|c|c|c|c|}
\hline Companies & $R^{2}$ & S.E. of reg & Schwarz criterion & F-statistic & Durbin-Watson stat & Prob (F-Stat) \\
\hline Adani Ports \& SEZ & 0.84 & 0.74 & 2.62 & 74.82 & 1.80 & 0.000000 \\
\hline Asian Paints & 0.56 & 0.42 & 1.30 & 36.25 & 1.94 & 0.000000 \\
\hline Axis Bank & 0.28 & 0.47 & 1.58 & 7.42 & 2.04 & 0.000001 \\
\hline BhartiAirtel & 0.17 & 0.41 & 1.31 & 3.32 & 1.98 & 0.003018 \\
\hline Cipla & 0.36 & 0.39 & 1.13 & 21.23 & 1.87 & 0.000000 \\
\hline Coal India & 0.07 & 0.47 & 1.51 & 1.72 & 1.96 & 0.170378 \\
\hline Dr. Reddy's Laboratories & 0.14 & 0.39 & 1.16 & 3.67 & 2.05 & 0.004048 \\
\hline HDFC Bank & 0.19 & 0.36 & 1.00 & 5.31 & 1.97 & 0.000199 \\
\hline Hero MotoCorp & 0.56 & 0.46 & 1.54 & 28.38 & 1.99 & 0.000000 \\
\hline Hindustan Unilever & 0.11 & 0.37 & 1.05 & 2.80 & 2.02 & 0.019980 \\
\hline $\begin{array}{l}\text { Housing Development } \\
\text { Finance Corporation }\end{array}$ & 0.00 & 1.67 & 3.90 & Not-fit & 1.85 & Not-fit \\
\hline ICICI Bank & 0.43 & 0.31 & 0.78 & 14.21 & 2.00 & 0.0000000 \\
\hline Infosys & 0.27 & 0.32 & 1.02 & 4.59 & 1.95 & 0.0000380 \\
\hline ITC & 0.09 & 0.57 & 1.85 & 3.63 & 1.96 & 0.0151640 \\
\hline Kotak Mahindra Bank & 0.49 & 0.40 & 1.24 & 27.44 & 2.01 & 0.0000000 \\
\hline Larsen \& Toubro & 0.12 & 0.53 & 1.81 & 3.20 & 1.84 & 0.0096880 \\
\hline Lupin & 0.13 & 0.44 & 1.27 & 8.40 & 2.03 & 0.0003900 \\
\hline Mahindra \& Mahindra & 0.20 & 0.42 & 1.50 & 2.99 & 1.87 & 0.0031940 \\
\hline Maruti Suzuki & 0.50 & 0.52 & 1.67 & 58.24 & 1.99 & 0.0000000 \\
\hline NTPC & 0.31 & 0.35 & 1.15 & 5.37 & 2.03 & 0.0000040 \\
\hline $\begin{array}{l}\text { Oil and Natural Gas } \\
\text { Corporation }\end{array}$ & 0.44 & 0.81 & 2.57 & 29.95 & 1.91 & 0.0000000 \\
\hline $\begin{array}{l}\text { Power Grid Corporation of } \\
\text { India }\end{array}$ & 0.05 & 0.40 & 1.10 & 2.83 & 2.02 & 0.0631510 \\
\hline Reliance Industries & 0.23 & 0.29 & 0.63 & 5.66 & 1.86 & 0.0000360 \\
\hline State Bank of India & 0.50 & 0.65 & 2.11 & 58.51 & 2.00 & 0.0000000 \\
\hline Sun Pharmaceutical & 0.55 & 0.39 & 1.32 & 16.50 & 2.07 & 0.0000000 \\
\hline Tata Consultancy Services & 0.54 & 0.39 & 1.35 & 15.97 & 1.94 & 0.0000000 \\
\hline Tata Motors & 0.52 & 0.49 & 1.75 & 14.75 & 2.02 & 0.0000000 \\
\hline Tata Motors DVR & 0.42 & 0.59 & 2.14 & 7.60 & 2.00 & 0.0000000 \\
\hline Tata Steel & 0.08 & 0.48 & 1.59 & 1.91 & 2.02 & 0.0983130 \\
\hline Wipro & 0.04 & 1.19 & 3.28 & 2.33 & 1.92 & 0.1014750 \\
\hline
\end{tabular}

Figure 3 shown historical and forecasted beta values for the period of April 2007 to March 2018. From April 2007 to March 2017 data considered as historical data and remaining 2 years data considered as forecasted beta estimations. Figure 3 represents the fluctuations of the beta values. Except Housing development Finance corporation remaining all companies are showing high variability of betas.

The results of ARIMA estimation model is shown in Table 6. The R-Square represents the fitted model. Most of the companies are fitted in the model leaving HDFC Bank, Bharti Airtel, Dr. Reddy's Laboratories, Lupin, Larsen \& Toubro, Hindustan Unilever, ITC, Tata Steel, Coal India, Power Grid Corporation of India, Wipro and Housing Development Finance Corporation companies. 
Table 7 Measurements of forecast accuracy

\begin{tabular}{|c|c|c|}
\hline Forecast & RMSE & MAE \\
\hline ADANI_PORTS_S S & 0.841378 & 0.652633 \\
\hline ASIAN_PAINTS & 0.42077 & 0.321786 \\
\hline AXIS_BANK & 0.500367 & 0.387344 \\
\hline BHARTI_AIRTEL & 0.506822 & 0.431662 \\
\hline CIPLA & 0.46884 & 0.379596 \\
\hline COAL_INDIA & 0.578413 & 0.492412 \\
\hline DR_REDDY_S_LAB & 0.646997 & 0.539812 \\
\hline HDFC_BANK & 0.322295 & 0.282889 \\
\hline HERO_MOTOCORP & 0.41597 & 0.321013 \\
\hline HINDUSTAN_UNILE & 0.561764 & 0.477721 \\
\hline HOUSING_DEVELO & 3.30179 & 1.272049 \\
\hline ICICI_BANK & 0.63866 & 0.548679 \\
\hline INFOSYS & 0.414746 & 0.312569 \\
\hline ITC & 0.375254 & 0.290329 \\
\hline KOTAK_MAHINDRA_ & 0.417355 & 0.316470 \\
\hline LARSEN__ _TOUBRO & 0.354568 & 0.287889 \\
\hline LUPIN & 0.446219 & 0.346406 \\
\hline MAHINDRA_MAHI & 0.372881 & 0.308901 \\
\hline MARUTI_SUZUKI & 0.580104 & 0.450615 \\
\hline NTPC & 0.452623 & 0.395638 \\
\hline OIL_AND_NATURAL & 0.608324 & 0.474146 \\
\hline POWER_GRID_COR & 0.533949 & 0.461928 \\
\hline RELIANCE_INDUSTR & 0.353265 & 0.281110 \\
\hline STATE_BANK_OF_I & 0.582342 & 0.498306 \\
\hline SUN_PHARMACEUTI & 0.423818 & 0.334507 \\
\hline TATA_CONSULTANC & 0.638716 & 0.501766 \\
\hline TATA_MOTORS & 0.631745 & 0.491985 \\
\hline TATA_MOTORS_DVR & 0.687075 & 0.565276 \\
\hline TATA_STEEL & 0.733887 & 0.626166 \\
\hline WIPRO & 0.567257 & 0.494062 \\
\hline Simple mean & 0.130158 & 0.100902 \\
\hline Trimmed mean & 0.102722 & 0.085454 \\
\hline Simple median & 0.147315 & 0.117914 \\
\hline Least-squares & 0.151789 & 0.116337 \\
\hline Mean square error & 0.108251 & 0.084964 \\
\hline MSE ranks & 0.111369 & 0.090427 \\
\hline
\end{tabular}

Source: Compiled by authors

Forecasting

These companies are having less than $20 \%$ of R-Square. Standard Error Regression (S.E of Reg) represents how wrong the regression model. The smaller values of S.E of Reg. indicate that observations are closer to the fitted line. The alternative way of AIC is Schwarz Criterion (SC) (Schwarcz, S.L., 2008), it imposes a larger penalty for additional coefficients (Akaike 1987). Durbin -Watson (DW) statistic is used to measure the serial correlation of the residuals. The evidence of positive serial correlation could be exited 


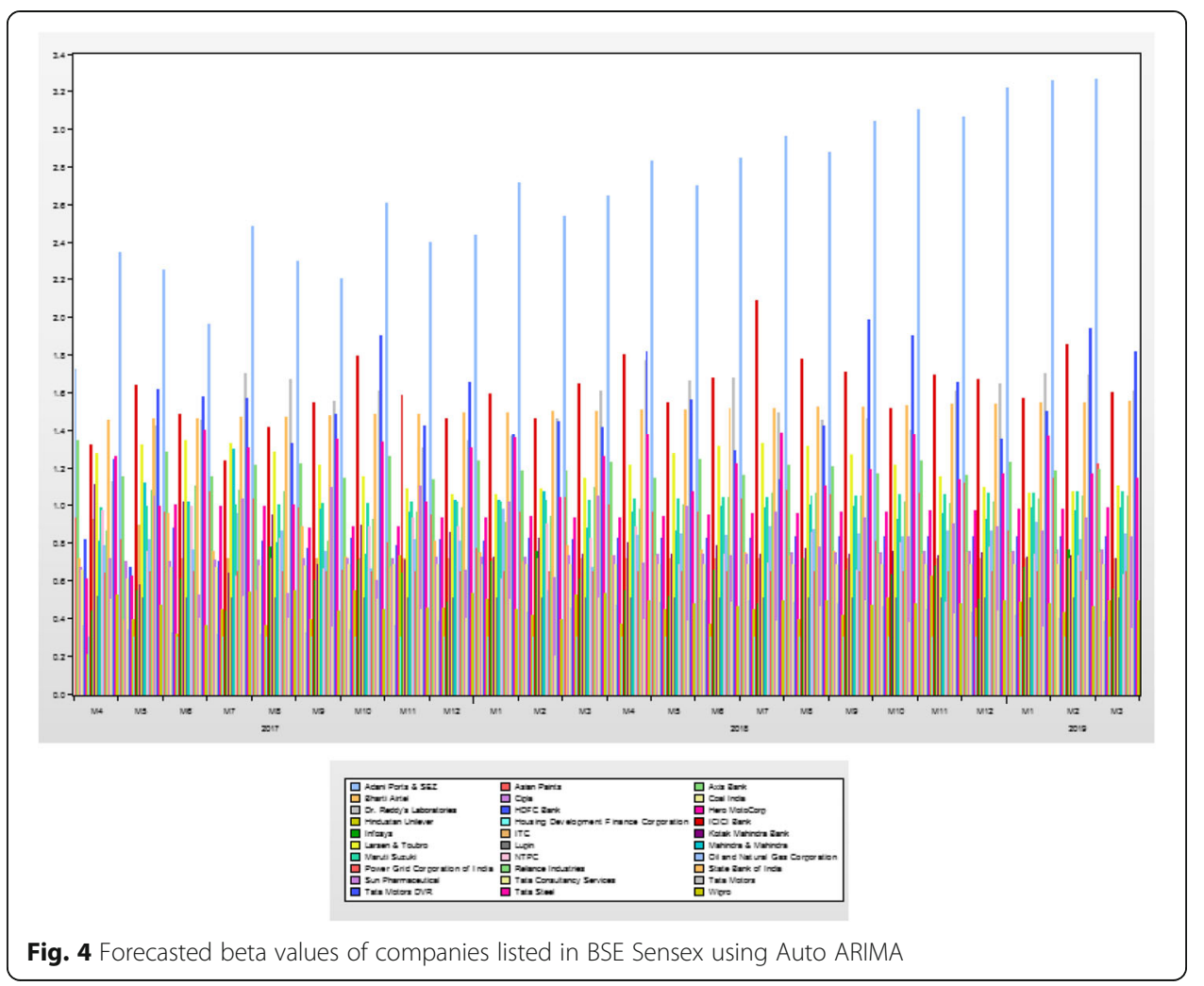

when the value of DW is less than 2. In the present study almost all companies DW is very close to 2 , this value indicates the presence of positive serial correlation in the residuals. F-Statistic represents the regression output from the hypothesis test that all of the slope coefficients are zero. The $p$-value denoted as prob. (F-Stat), which specifies the marginal significance level of F-test. The null hypothesis could be rejected when the $\mathrm{p}$-value is less than the significance level i.e. 0.05 , which shows that all slope coefficients are equal to zero. In this analysis, all the $p$-values are less than the F-stat values. Therefore, the null hypothesis could be rejected. The p-value is not significant in the case of Tata Steel and Wipro, remaining all companies are having 5\% significance level.

\section{Validation}

To measure the forecast of accuracy, authors run Forecast Evaluation model using E-views software for the sample period of April 2012 to March 2015, and evaluation sample period of April 2015 to March 2017. From the analysis, the accuracy

Table 8 Top 5 ranked companies in 3 divisions

\begin{tabular}{llllll}
\hline Moderate companies & Rank & Aggressive companies & Rank & Defensive companies & Rank \\
\hline Housing Development Finance Corporation & 1 & State Bank of India & 1 & Hero MotoCorp & 1 \\
Dr. Reddy's Laboratories & 2 & Tata Motors & 2 & Mahindra \& Mahindra & 2 \\
Tata Consultancy Services & 3 & Tata Motors DVR & 3 & Asian Paints & 3 \\
Hindustan Unilever & 4 & ICICI Bank & 4 & Reliance Industries & 4 \\
Wipro & 5 & Adani Ports \& SEZ & 5 & Maruti Suzuki & 5 \\
\hline
\end{tabular}

Source: Compiled by authors 
of the forecasting could be found for the validation purpose. To confirm the quality of accuracy Root Mean Square Error (RMSE) and Mean Absolute Error (MAE) were calculated based on errors between forecasted and actual data, which is presented in Table 7.

Table 7 shows the results of validation or test results between the forecasted and actual values. The MAE is always less than the RMSE values in all the cases of registered companies in BSE Sensex, which indicates that the error percentage is very less and the values of actual and forecast showing the almost same results. Therefore, the estimation ARIMA could be acceptable, and forecasted beta values are accurate.

\section{Findings}

From the analysis, authors have found the future beta values for the period of April 2017 to March 2019. From the Fig. 4 three categories of betas has been found. First one is moderate beta, which indicates the same instability as compared with Sensex and it equals to one. Second category is aggressive beta, which shows more instability when compared to Sensex and it express the beta greater than one.

Last one is defensive beta; it represents the less instability with Sensex comparison and it is less than one. According to the category the companies also segregated for the convenience of investors.

Lower rank represents the less risk and higher vice versa. Higher risk taking investors might get good returns in the future. Table 8 shows the less risky companies under three divisions (Moderate, Aggressive, Defensive) of companies. The investors can take investment decisions according to their choice.

\section{Conclusion}

Forecasting with Auto ARIMA provides a prediction based on historical data, in which data has been applied by first order difference to remove white noise problems. In this analysis Auto ARIMA estimated AIC values, which yielded the more accurate forecast over the ten years period. In validation, the forecasted values are compared with actual values over the hold back period of two years. From this analysis the more uncertainty has been found when the forecast period is long term period, less uncertainty exists in the case of short term period. From the analysis the different investors can choose companies according to their risk aversion.

\footnotetext{
Abbreviations

ACF: Auto Correlation Function; ADF: Augmented Dickie Fuller; AIC: Akaike Information Criteria; AR: Auto Regressive; ARIMA: Auto Regressive Integrated Moving Average; ARMA: Auto Regressive Moving Average; BSE: Bombay Stock Exchange; DW: Durbin -Watson; MA: Moving Average; MAE: Mean Absolute Error; PACF: Partial Auto Correlation Function; RMSE: Root Mean Square Error; S.E of Reg: Standard Error Regression; SC: Schwarz Criterion; Tata Motors DVR: Tata Motors Differential Voting Right Share
}

Availability of data and materials

Source of Data sets are available in http://www.bseindia.com and http://finance.yahoo.com. Analyzed data uploaded as supplementary material files.

Authors' contributions

Study of conception and design: MLC, VM, SNRK. Acquisition of data: MLC. Analysis and interpretation of data: MLC. Supervision: VM, SNRK. Drafting of manuscript: MLC. Critical revision: VM, SNRK. All authors read and approved the final manuscript. 
Pradesh, India. She is also working as Assistant Professor in University of Gondar, Gondar, Ethiopia. She has more than 5 publications in various international Journals / Conferences. Her research areas include Capital Asset Pricing, Dynamic changes in Stock market and Stock holders Interest.

Dr. Venkataramanaiah Malepati obtained his M.Com., M.Phil., and PhD from Sri Venkateswara University, Tirupati and MBA from Pondicherry University. At present, he is Professor of Management, Department of Management Studies at Golden Valley Instigated Campus, Madanapally. So far, he has published 34 research papers/articles in reputed/referred national/ international journals. Almost, the same number of papers/research articles has been presented in different national and international conferences/seminars. At present five books on his credit.

Dr. K. Siva Nageswara Rao is working as an Assistant Professor of School of Management Studies at Vignan Foundation for Science, Technology \& Research, Guntur, Andhra Pradesh, India. He received his MBA degree in Finance from Acharya Nagarjuna University, Andhra Pradesh, India and M.Phil Degree in Finance from MS University, Tiruelveli, Tamilnadu. He received his Ph.D degree from Acharya Nagarjuna University Guntur, Andhra Pradesh, India. He has 15 years of teaching experience. He has more than 20 publications in various National and International Journals/ Conferences. His main research interest includes Finance and Entrepreneurship.

\section{Competing interests}

Authors declare that they have no competing interests.

\section{Publisher's Note}

Springer Nature remains neutral with regard to jurisdictional claims in published maps and institutional affiliations.

\section{Author details}

'School of Management Studies, Vignan's Foundation for Science, Technology \& Research, Guntur, Andhra Pradesh, India. ${ }^{2}$ Institute of Management Studies, Golden Valley Integrated Campus (GVIC), Madanapalli, Chittoor 517 325, India.

\section{Received: 1 February 2018 Accepted: 1 October 2018}

\section{Published online: 22 October 2018}

\section{References}

Akaike H (1973) Information theory and an extension of the maximum likelihood principle. In: Petrov BN, Csaki BF

(eds) Second international symposium on information theory. AcademiaiKiado, Budapest, pp 267-281

Akaike H (1974) A new look at the statistical model identification. IEEE Trans Autom Control AC-19:716-723

Akaike H (1976) Canonical correlation analysis of time series and the use of an information criterion. In: Mehra RK, Lainiotis DG (eds) System identification. Academic Press, New York, pp 27-96

Akaike $H$ (1979) A Bayesian extension of the minimum AIC procedure of autogressive model fitting. Biometrika 66 : $237-242$

Akaike H (1981) Likelihood of a model and information criteria. J Econ 16:3-14

Akaike H (1987) Factor analysis and AIC. Psychometrika 52:317-332

Asteriou D, Hall SG (2015) Applied econometrics Third Edition. Palgrave Macmillan, London

Bianconi M, Hua X, Tan CM (2017) Determinants of systemic risk and information dissemination. Int Rev Econ Financ 38(2015):352-368 https://doi.org/10.1016/j.iref.2015.03.010

Black F (1976) Studies of stock market volatility changes. In: Proceedings of the 1976 meetings of the American Statistical Association, Business and Economic Statistics Section, pp 177-181

Box GEP, Jenkins GM (1976) Time series analysis: forecasting and control. Holden-Day, San Francisco

Brunnermeier M, Pedersen L (2009) Market liquidity and funding liquidity. Rev Financ Stud 22(6):2201-2238

Chakrabarty, K.C., (2012). Systemic Risk Assessment -the Cornerstone for the Pursuit of Financial Stability. Inaugural at the International Seminar on Operationalizing Tools for Macro-Financial Surveillance: Country Experiences, Organized by the Financial Stability Unit (FSU). Reserve Bank of India, Mumbai (3 April 2012)

Chan MK, Kwok S (2017) Risk-sharing, market imperfections, asset prices: evidence from China's stock market liberalization. J Bank Financ 84:166-187 https://doi.org/10.1016/j.jbankfin.2017.06.003

Chari A, Henry P (2004) Risk-sharing and asset prices: evidence from a natural experiment. J Financ 59:1295-1324

De Bandt O, Hartmann P (2000) Systemic risk: a survey. European Central Bank, ECB Working Paper No 35, November 2000, http://www.ecb.europa.eu/pub/pdf/scpwps/ecbwp035.pdf

Fama E, French K (2004) The capital asset pricing model: theory and evidence. J Econ Perspect 18:25-46

Garcia D (2013) Sentiment during recessions. J Financ 68(3):1267-1300

Hansen. L.P. 2013. Challenges in Identifying and Measuring Systemic Risk, NBER Working Papers 18505, National Bureau of Economic Research, Inc.

Jyothi Kumari, Jitendra Mahakud, Gourishankar S. Hiremath (2017), Determinants of idiosyncratic volatility: Evidence from the Indian stock market, Research in International Business and Finance. https://doi.org/10.1016/j.ribaf.2017.04.022

Kaufman G (1995) Comment on systemic risk. Res Financ Serv: Bank Financ Mark Syst Risk 7:47-52

Lindley DV (1968) The choice of variables in multiple regression (with discussion). J R Stat Soc Ser B 30:31-36

Lintner J (1965) The valuation of risky assets and the selection of risky investments in stock portfolios and capital budgets. Rev Econ Stat 47:13-37

Markowitz HM (1952) Portfolio selection. J Financ 7:77-91

Moussa A (2011) Contagion and systemic risk in financial networks Ph.D. Thesis. Columbia University, New York http:// academiccommons.columbia.edu/download/fedora_content/download/ac:131475/CONTENT/Moussa_columbia_0054D_ 10092.pd

Schwarcz SL (2008) Systemic risk. Georgetown Law J 97(1):193-249

Sharpe WF (1964) Capital asset prices: a theory of market equilibrium under conditions of risk. J Financ 19:425-442

Stone CJ (1981) Admissible selection of an accurate and parsimonious normal linear regression model. Ann Stat 9:475-485 